\title{
Stacking-Fault Formation and Propagation in 4H-SiC PiN Diodes*
}

\author{
R.E. STAHLBUSH, ${ }^{1}$ M. FATEMI, ${ }^{1}$ J.B. FEDISON,${ }^{2}$ S.D. ARTHUR, ${ }^{2}$ L.B. ROWLAND, ${ }^{2}$ and \\ S.WANG ${ }^{3}$
}

1.-Naval Research Laboratory, Washington, D.C. 20375. 2.-General Electric Corporate Research and Development Center, Niskayun, NY 12309. 3.-Sterling Semiconductor, Danbury, CT 06810

During the production process, some information was omitted from Figs. 1 and 4 for this paper. Corrected versions of these figures appear below.

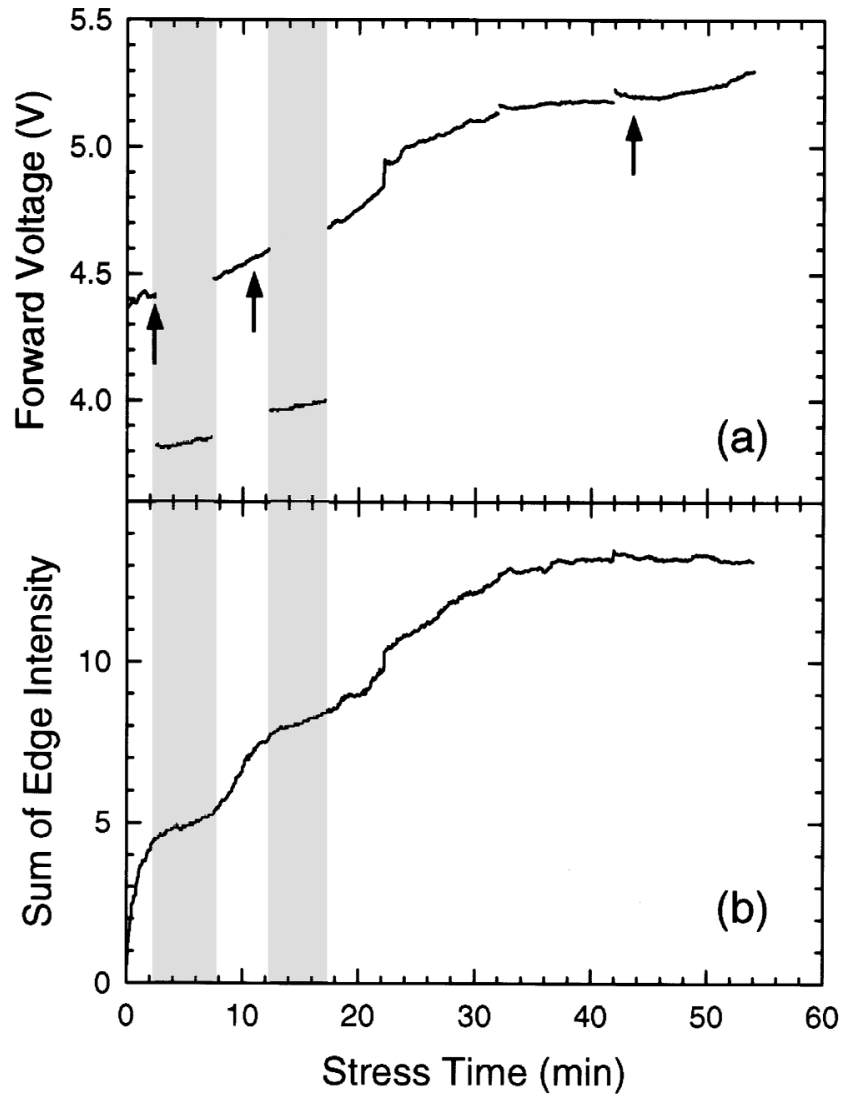

Fig. 1. Comparison of (a) forward-voltage degradation and (b) stacking-fault growth. The stressing current $1 \mathrm{~A}\left(160 \mathrm{~A} / \mathrm{cm}^{2}\right)$ was reduced to $0.5 \mathrm{~A}\left(80 \mathrm{~A} / \mathrm{cm}^{2}\right)$ during the two intervals shaded gray. The image pairs shown in Fig. 2 were taken at $\mathrm{t}=0 \mathrm{~min}, 2.4 \mathrm{~min}, 22 \mathrm{~min}$, and 44 min. Arrows show the last three times.

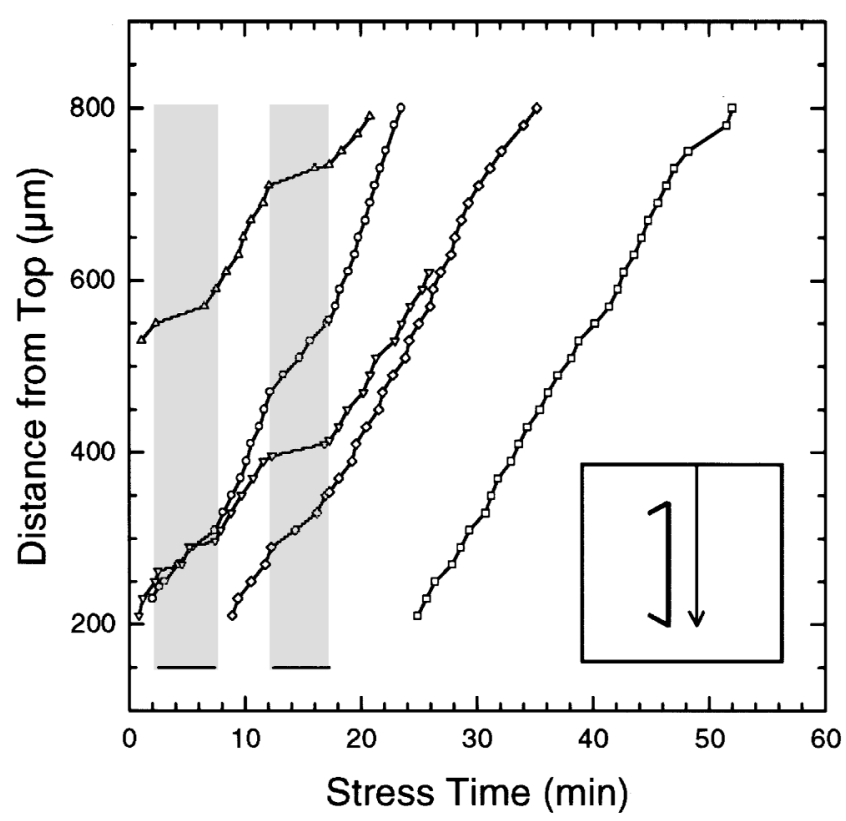

Fig. 4. Growth of stacking faults. The stressing current was 1 A (160 $\mathrm{A} / \mathrm{cm}^{2}$ ) except during the two intervals indicated in gray, when it was reduced to $0.5 \mathrm{~A}\left(80 \mathrm{~A} / \mathrm{cm}^{2}\right)$. The distance of the lower tip of the stacking fault from the top of the diode anode, as indicated in the inset, is plotted.

*J. Electron. Mater. 31 (5) (2002), pp. 370-375. 